\title{
An Empirical Study on the Innovation Acceptance of Wearable Mobile Computing: Pervasive Computing Perspective
}

\author{
Syakirah Mohamad Taib, Rebecca De Coster, Janerose Nyamu \\ Brunel University London, UK
}

\begin{abstract}
Extant literature on the acceptance of mobile computing has been developing in mobile banking services and in healthcare service, however, the study of users' acceptance of emerging wearable mobile computing is still at the early stages. This paper examines the development of a conceptual framework to understand the technology adoption factors for wearable mobile computing utilizing the Technology Acceptance Model (TAM), the Diffusion of Innovation Theory (DOI) and related factors on mobility and pervasive computing. Data of 272 respondents were collected using survey based questionnaires conducted in Malaysia. The findings of this research revealed the factors of mobility $(M O B)$, personalization $(P N)$ and perceived enjoyment (PE) achieved the highest average score by respondents, followed by perceived usefulness $(P U)$ and perceived ease of use (PEU), observability $(O B S)$, facilitating condition $(F C)$ and social influence (SI). Mobility (MOB) and perceived enjoyment $(P E)$ contribute the dominant factors for usage acceptance, while Perceived Usefulness (PU) from the established model TAM, still plays an important factor in predicting innovation adoption of wearable mobile computing.
\end{abstract}

\section{Introduction}

Wearable technology refers to electronic technologies which can be worn or attached on the body to facilitate interaction between the human and the computer to perform specific computing tasks [1]. This is different to mobile smartphones in which are carried and are the handheld devices. Many studies in the literature of mobile technology has been well developed, yet, on-body technology is still emerging stages and demands growing attention.

Wearable technology is expected to grow in this digital era, wearable devices include smartwatches, fitness trackers, augmented and virtual reality are forecasted to become mainstream in this new information era, however, there are limited studies to investigate the innovation and diffusion of wearable mobile computing and usage decisions, moreover, the deployment of this technology innovation is still at its infancy stage [2][3]. It is imperative to understand how the potential users of the emerging technology gain value from the innovation of the technology, consequently increasing users' diffusion and global market acceptance.

The phenomena of mobile phones in our daily activities has reached the mass adoption especially in the Malaysian context [4], mobile services such as mobile internet, mobile banking, online shopping, media socializing and internet surfing have become common daily activities. Studies on acceptance of mobile computing has been developing such as in mobile banking services and in healthcare service, however, the study of users' acceptance about the emergence of wearable mobile computing is still at the early stages. Reference [1], wearable computing has built-up research opportunities in artificial intelligence, mobile computing, or in human computer interaction. Wearable mobile computing will gain value from the vision of Pervasive Computing, as in [5] stated "the most profound technologies are those that disappear".

\section{Theoretical background and conceptual framework}

\subsection{Wearable mobile computing}

Potential users in a social system may not accept or adopt an innovation at the same time, some may like or dislike wearing any of these wearable devices. Wearable computing enhances personal computing with continuously worn, smart assistants that may augment memory and physical abilities. As wearable computing technology may become mainstream in human daily lives, the technology's acceptance understanding and growing research should be considered especially in users' acceptance of this advance wearable computing paradigm.

Mobility is increasingly an essential part of everyday life, new technological innovation may increasingly need to support mobility. Hence, the research agenda of pervasive computing will likely be driven by advances in mobile computing. Wearable computing can be any small devices, wristmounted systems to a large backpack computer. In most applications, the wearable devices comprises possibly display connected, wireless communications hardware and some input device, such as a touch pad. This combination has predominantly improved user performance in applications such as aircraft 
maintenance, navigational support and vehicle inspection.

User's environments can be made aware when a computer is worn. Context-sensitive applications can be developed to accomplish the response between human, computer, and environment. An early example of this technology was the Touring Machine, developed by Steve Feiner of Columbia University, a GPS (global positioning system) receiver and a head-orientation sensor were used to track the wearer as walked around and looking at various buildings on campus. Wearable computing devices are to attach to the user may augment reality, for example, computer generated images or audio on the real world and to provide context sensitivity [6].

Wearable mobile computing for this study refers to electronic technologies embedded worn on the human body [7] as unobtrusively as apparel such as a smartwatch continuously providing an interface to many computing tasks with the mobile smartphone acting as a hub [2]. There are various applications of wearable computing for instance for healthcare monitoring, fitness and wellness, infotainment, military and industrial. A lot of wearable mobile computing devices are emerging in the market including Apple iWatch, iRing, Sony Smart Band, Google Glass, Bluetooth Ring, and smart contact lenses for medical purposes [1]. These devices build on a lot of commercial activity related to smartwatches, in 2002, Microsoft announced the Smart Personal Object Technology (SPOT) watches, which became available in 2004 as well as Fossil released its Fossil Wrist PDA, which ran the Palm $\mathrm{OS}$, thus, it is imperative to examine the usage acceptance of this innovation [8]. Today's smartwatches use this modern mobile infrastructure, with Bluetooth links to a user's mobile phone, to leverage mobile apps as well as to more broadly connect to cloud services.

The perceived value of this wearable technology could not be fully realised until it is accepted and adopted by potential users which is the main focus of this research. The emergence of wearable mobile computing will accelerate the development of pervasive computing technologies and become a challenge in information technology research. The incorporation of wearable mobile computing devices and wireless personal area networks creating interesting experiences. WPANs such as Bluetooth enable seamless communication of wearable mobile computing. Smartwatch is improving the mobile phone experience in sustaining the innovation in the context of smartphones.

Nowadays, many smartwatches are interfacing with mobile phone for operation for examples including the Apple watch, Android watch and Pebble watch. On the hand, some smartwatches might be independent, but, most of the applications are still linked to the mobile smartphone for communication. Recent smartwatches with software and app stores development encouraging the developers and researchers to explore new experiences. People might think that a smartwatch could replace a smartphone, similar the smartphones replacing the PCs.

\subsection{Pervasive computing}

The purpose of wearable mobile computing is to provide computing services anytime and anywhere, which is a necessary element of pervasive computing. Mark Weiser has described the concept of pervasive or ubiquitous computing as "invisible, context-aware, embedded technology that will serve users in seamless and unconscious interaction".

Pervasive means "existing everywhere", Mark Weiser who realised the potential of ubiquitous/pervasive computing: embedding computers into the environment are invisible, while still being able to provide intended services and functions. Computing has evolved from desktops to mobile phones, ipads and tablets, a trend by which technology will become increasingly ingrained in movements and lives. Pervasive computing is the integration of computing power and sensors into wearable devices with the potential to enable anytime, anywhere communication of anything with anything else. Increasing devices support interfaces like natural communication with computing multisensory interaction. Pervasive computing devices predominantly use their intelligence to sense and interpret sensory information and are context aware.

After a phase of hardware and software progress, elements of pervasive computing that were uncommon previously are now workable commercial products for example, handheld and wearable computing devices and wireless technology to better understand Weiser's vision. Pervasive computing systems require support for interoperability, scalability, smartness, and invisibility to ensure that users have seamless access to computing whenever make timely, context-sensitive decisions. Pervasive computing, requires systems and devices that perceive context. Smartphones, e-readers, GPSenabled cameras, tablet computers, and other gadgets are already having a transformative effect on the development by interlinking the cyber and physical worlds [9].

Mobile computing addresses location and mobility management issues but in a reactive context responding to discrete events. Pervasive computing is more complex because it is proactive. Intelligent environments are a prerequisite to pervasive computing [10]. The number of pervasive devices is expected to multiply rapidly over the next few year, a market analysis has predicted that the number of pervasive devices will exceed the estimated 
worldwide population. As a consequence of this proliferation, many current technologies must be upgraded. In networks like the Internet also must modify existing applications to completely integrate these pervasive computing devices into existing social systems. While research challenges remain in all areas of pervasive computing, all the basic component technologies exist today for example mobile devices, sensors, and smart appliances.

Findings from this study could be applied as valuable insights for the future innovation in developing new wearable mobile computing technology in the pervasive computing environment due to potential users adopting wearable technology with different reasons. Pervasive computing is anytime, everywhere concept permitting access ranging from mobile phones to computing units embedded into daily objects, including barcodes, RFID, PDAs (personal digital assistants) and wireless communications [7], wearable computing are unique opportunities with the potential to commence wide spread adoption of Pervasive computing by embedding computers in many daily life items such as clothing, glasses, and other wearable objects.

\subsection{Conceptual framework}

The conceptual framework in this study has been developed from extant literature on mobile technology, adoption and pervasive computing in order to fill in the aforementioned gaps in this research, this study intends to identify important factors affecting the intention for potential users to accept wearable mobile computing. As the smartwatch is widely perceived as the next generation wearable devices, understanding users' perceptions and their relationships towards adoption of this technology will give insights for future researchers and practitioners in the related industry.

Various frameworks and models from many researchers utilised Technology Acceptance Model (TAM) to explain the technology acceptance in information technology (IT). There are also a number of different existing frameworks and predictive models in the literature for instance the ubiquitous computing acceptance model [11] and the factors of mobile computing [12]. Due to limited research concerning about technology innovation acceptance of mobile computing and wearable technology, this study was designed to develop the conceptual framework based on the integration factors from the Technology Acceptance Model (TAM), the Diffusion of Innovation Theory (DOI) and related factors on mobility and ubiquity of technology to understand the wearable technology acceptance.

The factors from the TAM introduced by [13] are perceived usefulness (PU) and perceived ease of use
(PEU), observability is selected from DOI [14], moreover, other selected factors for this research are mobility (MOB), personalization (PN), facilitating condition (FC) and perceived enjoyment (PE) as integrated factors, while social influence (SI) and mobile application (MA) as the determinants of key constructs which may affect the factors predicted. The proposed conceptual framework is shown in Figure 1.

Using this framework, the current wearable computing can be predicted for future products development and enhancing research area of wearable technology holistically. The contribution of this study is the integration of the established models (TAM and DOI) with related proposed factors from mobile technology factor, pervasive/ubiquitous factors to evaluate potential user usage acceptance, thus promising the diffusion of innovation. The development of the constructs (factors) for this research were selected from related literature and adapted to the context of wearable mobile computing from pervasive perspective, as shown in Table 1.

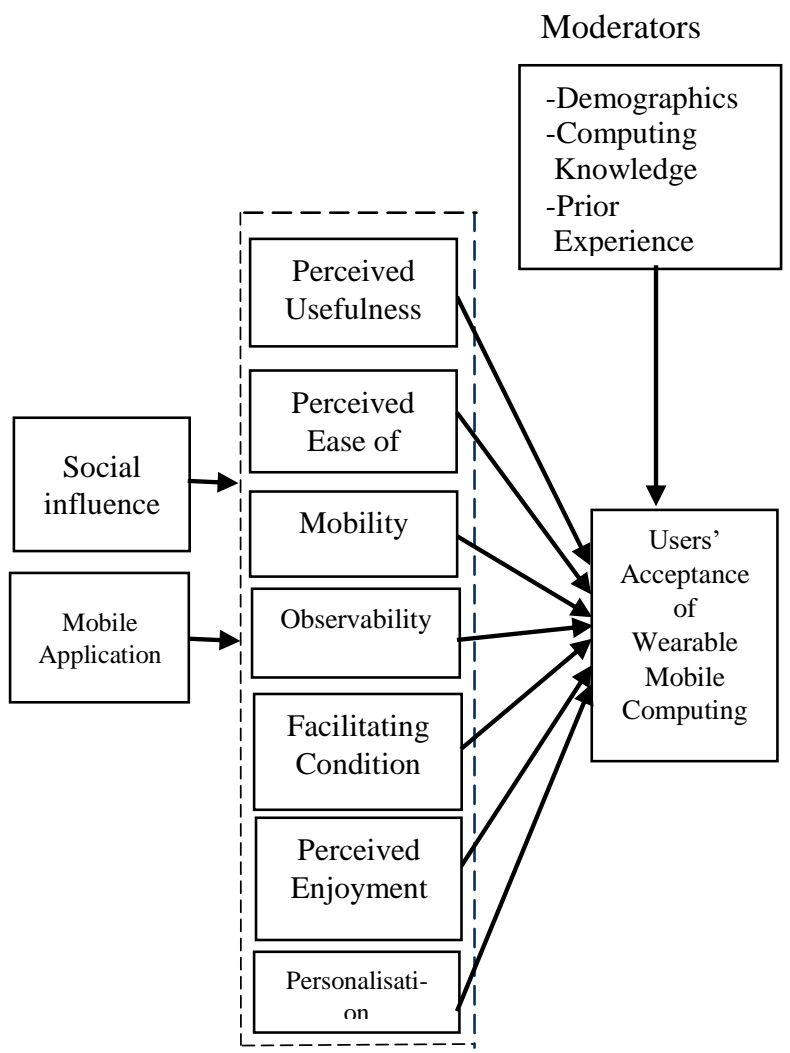

Figure. 1. The conceptual framework of wearable technology 
Table 1. The factors developed in the conceptual framework

\begin{tabular}{|c|c|}
\hline Factors & Definition \\
\hline $\begin{array}{l}\text { Perceived } \\
\text { Usefulness }\end{array}$ & $\begin{array}{l}\text { Perceived usefulness as the extent to } \\
\text { which an individual believes that } \\
\text { using a specific system would } \\
\text { improve his or her job performance. }\end{array}$ \\
\hline $\begin{array}{l}\text { Perceived } \\
\text { Ease of Use }\end{array}$ & $\begin{array}{l}\text { Perceived ease of use as the degree to } \\
\text { which an individual believes that } \\
\text { using a particular system would be } \\
\text { free of effort. }\end{array}$ \\
\hline $\begin{array}{l}\text { Observabili- } \\
\text { ty }\end{array}$ & $\begin{array}{l}\text { Observability is the degree of making } \\
\text { visible the results of innovation. }\end{array}$ \\
\hline Mobility & $\begin{array}{l}\text { Mobility is the factor for mobile } \\
\text { computing to provide pervasive and } \\
\text { ubiquitous connection in encouraging } \\
\text { users' behavioral intention to use the } \\
\text { services }\end{array}$ \\
\hline $\begin{array}{l}\text { Personaliza- } \\
\text { tion }\end{array}$ & $\begin{array}{l}\text { Personalization as the ability to } \\
\text { customise wearable technology } \\
\text { services to fit the user's preferences. }\end{array}$ \\
\hline $\begin{array}{l}\text { Facilitating } \\
\text { Condition }\end{array}$ & $\begin{array}{l}\text { Facilitating Condition is defined as } \\
\text { the degree to which an individual } \\
\text { believes that the conditions exist } \\
\text { which gives them control (or choice) } \\
\text { over whether they perform a } \\
\text { behavior. }\end{array}$ \\
\hline $\begin{array}{l}\text { Perceived } \\
\text { Enjoyment }\end{array}$ & $\begin{array}{l}\text { Perceived enjoyment is defined as an } \\
\text { interesting, fun, enjoyable, and } \\
\text { entertaining to adopt wearable } \\
\text { technology. }\end{array}$ \\
\hline $\begin{array}{l}\text { Social } \\
\text { Influence }\end{array}$ & $\begin{array}{l}\text { Social influence is defined as a user's } \\
\text { perception that most people who are } \\
\text { important to him think he should or } \\
\text { should not perform the behavior }\end{array}$ \\
\hline $\begin{array}{l}\text { Mobile } \\
\text { Application }\end{array}$ & $\begin{array}{l}\text { Mobile application usage with a } \\
\text { program designed that runs on a } \\
\text { mobile device (smart phone, tablet) } \\
\text { operated by the owner of the mobile } \\
\text { operating system, such as the Apple } \\
\text { App Store, Google Play, to access the } \\
\text { mobile services }\end{array}$ \\
\hline
\end{tabular}

- All the model factors are adapted from established literature, refer to conference paper [15].

\section{Research approach}

This paper presents the development of framework to understand the factors influencing the potential users' acceptance of wearable mobile technology, thus the appropriate research approach or method is essential to ensure the reliability of the research study.

The respondents are university students and employed personnel as the potential adopters, clustered from the central and southern region of Malaysia by utilizing clustering sampling based on the characteristic of prior internet knowledge and experience in mobile technology. Cluster sampling is a sampling technique cover a large geographical area while the sampling frame is not available [16]. From the clustered regions selected, the respondent of university students and professionals were selected in the study.

The data collection was conducted from December 2015 to February 2016, after research approval from Brunel University Research Ethic committee had been granted. Table 2 shows the sample profile for this study. This research employed survey based self-administered questionnaires (quantitative approach) with five-Point Likert scales, indicates the extent of agreement where 1=strongly disagree to $5=$ strongly agree adapted from literature.

Malaysia is divided into six main regions: Northern Region, Central Region, Southern Region, East Coast, Sabah and Sarawak. According to [17], for sample size calculation is $\mathrm{N}>50+(8 \times \mathrm{m})$, where $\mathrm{m}=$ number of independent variable (model factors), this study comprises seven factors, which $\mathrm{N}>50+(8$ $x$ 7) = N> 106 respondents, thus, for this study, the sample size of 272 respondents are sufficient and managed to be collected from Central and Southern Region, with $33.5 \%$ male and $66.5 \%$ of female, age group of 18-25 contributed the largest sample of $60.7 \%$ and the least is age group $45-54$ with $3.3 \%$ which is sufficient for further analysis.

\section{Results}

The reliability of the questionnaire has been tested using IBM SPSS version 20 to check the scale's internal consistency. The Cronbach alpha coefficient should be above 0.70 [17] and the Table 3 shows all the factors chosen above the suggested value and acceptable for further statistical analysis. Correlation is used to describe the strength and direction of the relationship between two variable. The strength of the relationship ranging from $\mathrm{r}=.01$ to 0.29 (small), $r=0.30$ to 0.49 (medium) and $r=0.50$ to 1.0 (large) [17]. Again, Table 3 shows the Pearson, $r$ correlation of dependent construct, Behavioral intention (BI) which is Users' Acceptance of Wearable Mobile Computing between independent constructs (SI, PU, PEU, OBS, $\mathrm{MOB}, \mathrm{FC}$ and $\mathrm{PE}$ ), there was a positive correlation of all the factors selected indicate the positive relationship.

According to the results shown, MOB, PE and PN are the dominant predicted factors for potential users to adopt the wearable mobile technology with the highest average scores for factor differences in gender, age and position. The nature of wearable technology in enhancing pervasive computing, mobility (MOB) and perceived enjoyment (PE) contribute the dominant factor for usage acceptance while Perceived Usefulness (PU) from established model TAM, still plays an important factor in 
predicting innovation adoption of wearable mobile computing. From multiple regression tests, Perceived Usefulness (PU) indicating the largest unique contribution, followed by Mobility (MOB) linked factor with Observability (OBS), Perceived Enjoyment (PE) linked factor with Personalisation (PN) and Facilitating Condition (FC) are the significant predicted factors with $61 \%$ (R square) of variance explained for users' acceptance of wearable mobile technology. Therefore, these predicted factors may positively influence innovation diffusion of wearable mobile technology in Malaysia.

Table 2. Sample profile

\begin{tabular}{|l|l|c|c|}
\hline \multicolumn{2}{|l|}{ Characteristic N=272 } & Frequency & $\begin{array}{c}\text { Percent } \\
(\%)\end{array}$ \\
\hline \multirow{3}{*}{ Gender } & Male & 91 & 33.5 \\
\cline { 2 - 4 } & Female & 181 & 66.5 \\
\hline \multirow{4}{*}{ Age } & $18-26$ & 165 & 60.7 \\
\cline { 2 - 4 } & $27-35$ & 82 & 30.1 \\
\cline { 2 - 4 } & $36-44$ & 16 & 5.9 \\
\cline { 2 - 4 } & $45-54$ & 9 & 3.3 \\
\hline \multirow{4}{*}{ Position } & Employed & 130 & 47.8 \\
\cline { 2 - 4 } & Student & 140 & 51.5 \\
\cline { 2 - 4 } & Others & 2 & 0.7 \\
\hline \multirow{2}{*}{\begin{tabular}{l} 
Purpose of $\begin{array}{l}\text { mobile } \\
\text { usage }\end{array}$ \\
\cline { 2 - 4 }
\end{tabular}} & Business & 21 & 7.7 \\
\cline { 2 - 4 } & Personal & 211 & 77.6 \\
\cline { 2 - 4 } & Study & 40 & 14.7 \\
\hline
\end{tabular}

Table 3. Reliability test, Pearson correlation $\mathrm{r}$ and multiple regression

\begin{tabular}{|c|c|c|c|c|}
\hline \multirow{2}{*}{ Factors } & \multirow{2}{*}{$\begin{array}{c}\text { Cronbach } \\
\text { Alpha } \\
\mathrm{N}=272\end{array}$} & \multirow{2}{*}{\begin{tabular}{|c|} 
Pearson \\
Correlation, \\
$\mathbf{r}$ \\
Behavioral \\
intention \\
(BI) \\
\end{tabular}} & \multicolumn{2}{|c|}{$\begin{array}{c}\text { Multiple } \\
\text { Regression }\end{array}$} \\
\hline & & & Beta & Sig. \\
\hline $\begin{array}{c}\text { Behavioral } \\
\text { intention }(\mathrm{BI})\end{array}$ & 0.93 & 1.000 & - & - \\
\hline $\begin{array}{c}\text { Social } \\
\text { influence }(\mathrm{SI})\end{array}$ & 0.89 & $.596 * *$ & - & - \\
\hline $\begin{array}{c}\text { Perceived } \\
\text { Usefulness } \\
(\mathrm{PU})\end{array}$ & 0.94 & $.733 * *$ & 0.425 & .000 \\
\hline $\begin{array}{c}\text { Perceived ease } \\
\text { of use (PEU) }\end{array}$ & 0.93 & $.636 * *$ & 0.095 & .135 \\
\hline $\begin{array}{c}\text { Observability } \\
(\mathrm{OBS})\end{array}$ & 0.88 & $.574 * *$ & \multirow{2}{*}{0.184} & \multirow{2}{*}{.007} \\
\hline $\begin{array}{c}\text { Mobility } \\
\text { (MOB) }\end{array}$ & 0.92 & $.686 * *$ & & \\
\hline $\begin{array}{c}\text { Facilitating } \\
\text { condition }(\mathrm{FC})\end{array}$ & 0.93 & $.602 * *$ & \multirow{3}{*}{0.174} & \multirow{3}{*}{.014} \\
\hline $\begin{array}{c}\text { Perceived } \\
\text { enjoyment }(\mathrm{PE})\end{array}$ & 0.93 & $.670 * *$ & & \\
\hline $\begin{array}{l}\text { Personalization } \\
(\mathrm{PN})\end{array}$ & - & $.512 * *$ & & \\
\hline
\end{tabular}

In summary, results identify Perceived Usefulness (PU), the linked factors comprise Mobility (MOB) with Observability (OBS), further, linked factor comprise Perceived Enjoyment (PE) with Personalisation (PN) and Facilitating Condition (FC). It was shown to be significant predicted factors for potential users to adopt the wearable mobile technology with $61 \%$ (R square) of variance explained in BI.

\section{Research findings and discussion}

The main contribution of this study is the integration of TAM model, with DOI factor, mobility and pervasive factors to demonstrate the significant predictors of users' intentions and acceptance to adopt wearable mobile technology in the Malaysian context. The selected factors of social influence (SI), perceived usefulness (PU), perceived ease of use (PEU), observability (OBS), mobility (MOB), facilitating condition (FC), perceived enjoyment $(\mathrm{PE})$ and personalization (PN) were analyzed based on gender (Figure. 2), age (Figure. 3) and based on position (Figure. 4).

The model factor score differences based on gender in Figure. 2 shows that MOB, PN and PE contribute to the highest average score for both male and female followed by PU, PEU (the two TAM factors), OBS, FC and then lastly, SI. Both male and female have almost similar score for each model factor, showing that gender has no different in accepting the new innovation of wearable mobile computing, it may likely reflect sample chosen are educated with computing knowledge and mobile experience. The factor scores difference based on age in Figure. 3, also shows that MOB, PE and PN have the highest average score followed by $\mathrm{PU}$, however, age group 36-44 reported the highest average score for OBS, MOB and PE, which may reflect the priorities of people at midcareer stage; a study conducted by [18], found that age is an important factor, where users under 34 years of age show strong demand for smartwatches with significant on result demonstrability, while enjoyment is significant only for people aged between 35 and 54, it was similar to this study as perceived enjoyment was found to have higher mean score for all age categories. According to [18], this is likely because the potential users usually have a higher social position, better employment, and higher income.

TAM is recognized as an established framework, however, some of TAM factor are not applicable to this innovative advancement of technology development for example in [3][18], the study found that PEU is not a predictor for using the smartwatch, similar to this study, through the regression test done, PEU was found not a significant predictor for accepting wearable mobile technology. Moreover, in 
[19][20] found that PU was not a significant predictor for intention to adopt the smartwatches however, in this study, PU was found as the highest contributor in predicting the users' acceptance, it demonstrates potential users might expect smartwatches to be easy to use, likely they are all smartphone users with internet and mobile technology experiences. Hence, existing theories and models, such as the Technology Acceptance Model (TAM), need to be extended to fit the new context of wearable technologies perspective. However, the study's greater theoretical contribution is its integration of the model factors to deepen understanding how potential users perceived to adopt this new emerging technology for better lives.

For the factor scores difference based on position in Figure. 4, only 2 groups are included in the study as under the group 'others' only has 2 respondents (retained for the completeness of data collection). Again, result shows that MOB, PE and PN has the highest average score for both groups: employed personnel and students. Overall, it seems that all model factors have the high average mean score showing users' willing to adopt this technology. The outcome which is behavioral intention or users' acceptance of wearable mobile technology was analyzed based on age and gender in Figure. 5, results showed that the highest average score is for two age group 18-26 and 27-35 while male has the highest average score compared to female for age group 36-44. This findings demonstrate that younger age are more likely to accept the technology innovation, in contrast female at older age are shown to be also more likely to adopt this emerging technology compared to male, this result showed the sample chosen reflected the female were the professional whom are the potential users with intention to accept the innovation.

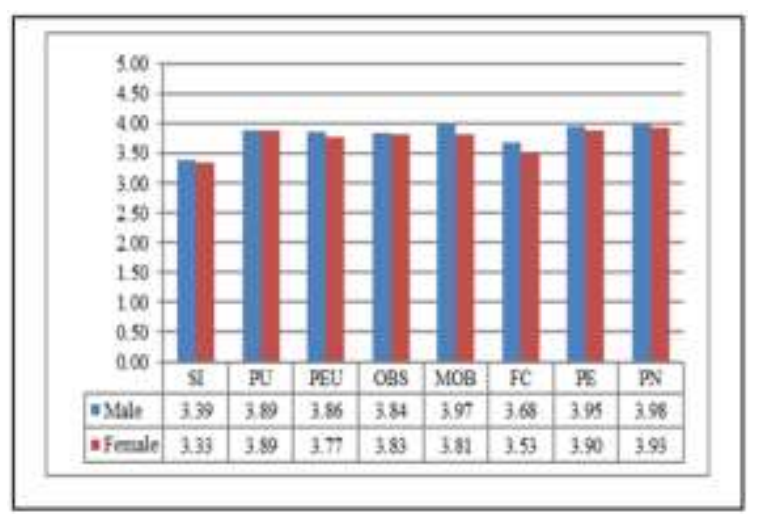

Figure 2. Factor score difference based on gender

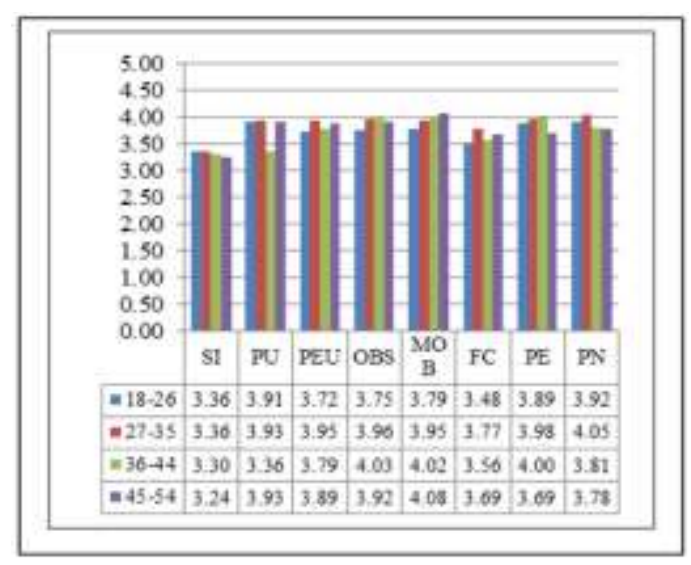

Figure 3. Factor score difference based on age

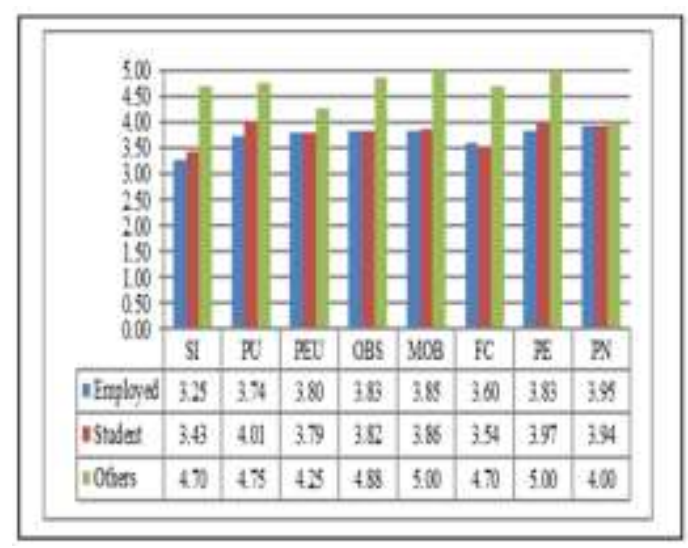

Figure 4. Factor score difference based on position

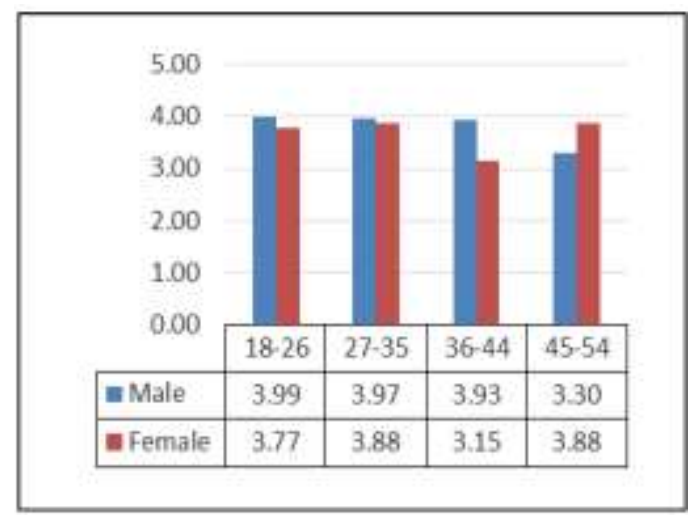

Figure 5. Behavioral intention average scores based on age and gender

\section{Conclusion}

From this study, a conceptual framework has been developed with the predicted factors for potential users to adopt the wearable mobile computing. The conceptual framework developed underpinning this study composed the established 
models integrated with the mobility and pervasive computing factors to understand the impact of the innovation of the new enabling technology. The empirical data studied to examine the model factors through comparing average score and regression testing.

Malaysia as a developing country may adopt new emerging technology for beneficial of daily activities in this challenging information society. From multiple regression test, the predicted model factors explained $61 \%$ ( $\mathrm{R}$ square) of the variance for users' acceptance of wearable mobile technology in Malaysia. Therefore, these predicted factors may positively influence innovation diffusion of wearable mobile technology in Malaysia.

\section{Acknowledgment}

We acknowledge all the respondents who kindly participated in this study. We also acknowledge that an earlier version of this material was presented in International Conference on Information Society (isociety 2016), Technical Co-sponsored by IEEE UK/RI Computer Chapter held on 10-13 October 2016, Dublin, Ireland.

\section{References}

[1] S. Jhajharia, S. K. Pal, and S. Verma, "Wearable Computing and its Application," Int. J. Comput. Sci. Inf. Technol., vol. 5, no. 4, pp. 5700-5704, 2014.

[2] J. Wei, "How Wearables Intersect with the Cloud and the Internet of Things," IEEE Consumer Electronics Magazine, pp. 53-56, 2014.

[3] J. Choi and S. Kim, "Is the smartwatch an IT product or a fashion product? A study on factors affecting the intention to use smartwatches," Comput. Human Behav., vol. 63, pp. 777-786, 2016.

[4] M. A. Osman, A. Z. Talib, Z. A. Sanusi, T. ShiangYen, and A. S. Alwi, "A Study of the Trend of Smartphone and its Usage Behavior in Malaysia," Int. J. New Comput. Archit. Their Appl., vol. 2, no. 1, pp. 275-286, 2012.

[5] M. Weiser, "The Computer for the 21st Century," Scientific American, vol. 265, no. 3. pp. 94-104, 1991.

[6] M. Billinghurst and T. Starner, "New Ways to Manage Information," Computer, vol. 32, no. 1, pp. 57-64, 1999.

[7] C. J. Anumba and X. Wang, "Mobile and Pervasive Computing in Construction: An Introduction," Mob. Pervasive Comput. Constr., vol. 1, pp. 1-10, 2012.

[8] K. Lyons, "Smartwatch Innovation: Exploring a Watch-First Model," IEEE Pervasive Computing, vol. 15, no. 1, pp. 10-13, 2016.

[9] M. Conti, S. K. Das, C. Bisdikian, M. Kumar, L. M. Ni, A. Passarella, G. Roussos, G. Tröster, G. Tsudik, and F.
Zambonelli, "Looking ahead in pervasive computing: Challenges and opportunities in the era of cyber-physical convergence," Pervasive Mob. Comput., vol. 8, no. 1, pp. 2-21, 2012.

[10] D. Saha and A. Mukherjee, "Pervasive Computing - A Paradigm for the 21st Century," IEEE Comput., vol. 36, no. 3, pp. 25-31, 2003.

[11] S. Moran, T. Nishida, and K. Nakata, "Comparing British and Japanese perceptions of a wearable ubiquitous monitoring device," IEEE Technology and Society Magazine, vol. 32 (4), pp. 45-49, 2013.

[12] T. M. Faziharudean and T. Li-Ly, "Consumers' behavioral intentions to use mobile data services in Malaysia,” African J. Bus. Manag., vol. 5, no. 5, pp. 18111821, 2011.

[13] F. D. Davis, "Perceived usefulness, perceived ease of use, and user acceptance of Information Technology," MIS Q., pp. 319-340, 1989.

[14] E. M. Rogers, Diffusion of Innovations, Fourth Ed. The Free Press, New York, 1995.

[15] S. M. Taib, R. De Coster, and J. Nyamu, "Innovation Diffusion of Wearable Mobile Computing: Pervasive Computing Perspective," in International Conference on Information Society (i-Society 2016), Technical Co sponsored by IEEE UK/RI Computer Chapter, 2016, pp. 97-101.

[16] Z. Awang, Research methodology and data analysis, 2nd ed. Shah Alam, Malaysia: UiTM Press, 2012.

[17] J. Pallant, SPSS Survival: A step by step guide to data analysis using IBM SPSS, 5th ed. New York, USA: The McGraw.Hill Companies, 2013.

[18] L. H. Wu, L. C. Wu, and S. C. Chang, "Exploring consumers' intention to accept smartwatch," Comput. Human Behav., vol. 64, pp. 383-392, 2016.

[19] S. H. W. Chuah, P. A. Rauschnabel, N. Krey, B. Nguyen, T. Ramayah, and S. Lade, "Wearable technologies: The role of usefulness and visibility in smartwatch adoption," Comput. Human Behav., vol. 65, pp. 276-284, 2016.

[20] K. J. Kim and D.-H. Shin, "An acceptance model for smart watches: Implications for the adoption of future wearable technology," Internet Res., vol. 25, no. 4, pp. 527-541, 2015. 